rehabilitation medicine, 454-458.

5. Lê Đức Hinh và CS (2008), Tai biến mạch máu não. Nhà xuất bản Y hoc, 29 - 47

6. Trân Văn Chương (2010), Phục hồi chức năng bênh nhân liêt nửa người do tai biến mach máu nã̃o, Vật lý trị liệu - Phục hồi chức năng. Nhà xuất bản Y học Hà Nội, 574 - 603.
7. Borboni A, Mor M, Faglia R (2016), Gloreha hand robotic rehabilitation : design, medical model and experiments. J Dyn Syst Meas control, 138.

8. Jorge H, Giovanni T, Silvia G (2015), Efficacy of short-term robot-assisted rehabilitation in patients with hand paralysis after stroke: A randomized clinical trial. AAHS, Hand, 1-8.

\title{
KIẾN THỨC, THỰC HÀNH VÀ CÁC YẾU TỐ LIÊN QUAN VỀ PHÒNG CHỐNG BÊNH HO GÀ CỦA CÁC BÀ ME Có CON DƯớI 5 TUỔI TÅI TỈNH NAM ĐINNH NĂM 2020
}

\section{TÓM TẮT}

Nghiên cứu mô tả cắt ngang được thực hiện trên 384 bà me có con dưới 5 tuổi nhằm mô tả thực trang và các yểu tố liên quan đến kiến thức, thức hành phòng chống bệnh ho gà của các bà mẹ tại tỉnh Nam Định từ tháng $9 / 2020$ đến tháng $5 / 2021$. Kết quả nghiên cứu cho thấy: Tỷ lệ bà mẹ đạt kiến thức chung về phòng bệnh ho gà thấp $(28,9 \%)$, tuy nhiên tỷ lệ bà mẹ đạt thực hành phòng bệnh ho gà khá cao $(70,6 \%)$. Các yếu tố liên quan tới kiến thức của bà me là: địa điểm sinh sống, số con của bà mẹ và tiếp cận được nguồn thông tin truyền thông về ho gà. Nghiển cứu có tìm thấy mối liên quan có ý nghĩa thống kê giữa thực hành với nơi ở và trình độ học vấn. Công tác truyền thông, giáo dục sức khoẻ cần phải được tăng cường hơn nữa, lựa chọn các phương pháp truyền thông phù hợp, thời điểm truyên thông thích hợp, nâng cao trình độ cho cán bộ y tế cơ sở giúp nâng cao kiến thức, thực hành phòng bệnh của các bà mẹ.

Tư khóa: bệnh ho gà, kiến thức, thực hành

\section{SUMMARY}

THE SITUATION AND RELATED FACTORS TO KNOWLEDGE AND PRACTICE OF PERTUSSIS PREVENTION AMONG MOTHERS WITH CHILDREN UNDER 5 YEARS OLD IN NAM DINH PROVINCE FROM SEPTEMBER 2020 TO MAY 2021

A cross - sectional descriptive study was conducted on 384 mothers with children under five years of age to describe the situation and some factors related to knowledge and practice of pertussis prevention from September 2020 to May 2021. The results showed that: The percentage of mothers who had good general knowledge about preventing pertussis disease is low $(28.9 \%)$, but the prevalence of good practice of mothers about pertussis prevention is quite high $(70.6 \%)$. Related factors to mother's knowledge are:

*Trường Đại hơ Y Dược Thái Binh

Chịu trách nhiệm chính: Ngô Văn Mạnh

Email: manhsdh@gmail.com

Ngày nhận bài: 17.6.2021

Ngày phản biên khoa hoc: 16.8.2021

Ngày duyệt bài: 24.8.2021
Ngô Văn Mạnh*, Bùi Thị Huyền Diệu*

place of residence, number of children and access to media information about pertussis. The study found a statistically significant association between practice and residence and educational attainment. Health communication and education need to be further strengthened, choosing appropriate communication methods, appropriate communication time, improve the qualifications of local health workers,... to help improve knowledge and practice prevention of mothers.

Keywords: pertussis; knowledge; practic

\section{I. ĐĂT VẤN ĐỀ}

Bệnh ho gà là môt truyền nhiễm cấp tính đường hô hấp, có thể gây ra các biến chứng nghiêm trọng, rất dễ lây tữ người sang người và thường xảy ra ở trẻ nhỏ. Mặc dù bênh đã có vắc xin dự phòng nhưng bênh vẫn chưa hoàn toàn được kiểm soát và có thể gây tử vong. Tổ chức $y$ tế thế giới $(\mathrm{WHO})$ ước tính, hàng năm vẫn có 24 triệu ca mắc ho gà trên toàn thế giới và gây nên khoảng 160.700 ca tử vong, phần lớn trong số đó là trẻ dưới 5 tuổi[1]. Trên thế giới năm 2018 vẫn còn 151.074 ca mắc; năm 2019 tỷ lê bao phủ vắc xin bach hầu-ho gà-uốn ván (DPT) mũi 3 mới chỉ đạt $85 \%$ [2]. Tại Việt Nam sau nhiều năm tiêm vắc xin DPT, tỷ lệ mắc và chết của bênh ho gà đã giảm rất rõ rệt. Tỷ lệ mắc hàng năm dao động từ 0,059-1,78 trên 100.000 dân. Sau khi giảm vào năm 2004, số ca mắc đã được báo cáo ngày càng tăng kể từ năm 2015. Tích Iũy năm 2019, cả nước ghi nhận 1.227 trường hợp mắc ho gà, 01 trường hợp tử vong. So với năm 2018 tỷ lệ mắc là $0.43 / 100.000$ dân (676 trường hợp mắc, 02 tử vong), số mắc tăng $81,5 \%[3],[4],[5]$.

Để phòng chống bệnh ho gà thì việc hiểu biết và thực hiện tốt của người dân nói chung và của các bà me nói riêng về phòng chống bệnh ho gà sẽ góp phần rất lớn trong công tác phòng chống dịch. Tuy nhiên trên thực tế, không phải toàn bộ cha/ mẹ/ người chăm sóc chính đều có kiến 
thức, thực hành (KP) tốt về vấn đề này. Như tại Móng Cái, Quảng Ninh nghiên cứu năm 2015 cho thấy: hiểu biết của các bà me về các bệnh phòng được nhờ tiêm chủng mở rộng còn hạn chế, chỉ có $78 \%$ các bà me hiểu được bệnh ho gà có thể phòng được bằng tiêm vắc xin; tỷ lệ tiêm DPT1 là $97,6 \%$ và DPT3 là $70 \%$ từ đó cho thấy tỷ lệ bỏ mũi tiêm giữa mũi đầu tiên và mũi thứ 3 là $27,6 \%[6]$.

Tại tỉnh Nam Định, trong những năm gần đây ghi nhận sự gia tăng các trường hợp mắc ho gà, sau nhiều năm liên tục không có ca tử vong do ho gà, năm 2017 tỉnh Nam Định ghi nhân một trường hợp tử vong do ho gà và điều đặc biệt nhiều trường hợp mắc là trẻ dưới 2 tháng tuổi lứa tuổi chưa được tiêm vắc xin phòng bệnh ho gà chủ động, đặc hiệu. Từ thực trạng trên với mong muốn đưa ra cái nhìn chung nhất về kiến thức, thực hành và một số yếu tố liên quan đến phòng chống bệnh ho gà của các bà me có con dưới 5 tuổi từ đó giúp xây dựng các giải pháp nhằm giảm số mắc bệnh ho gà tại Nam Định, chúng tôi đã tiến hành nghiên cứu này.

\section{II. ĐỐI TƯớNG VÀ PHƯƠ'NG PHÁP NGHIÊN CỨU}

2.1 Đối tượng nghiên cứu. Bà mẹ đang nuôi con dưới 5 tuổi

Tiêu chuân lựa chọn: Bà me hiện đang nuôi con dưới 5 tuổi tại 3 xã/phường được lựa chọn tại tỉnh Nam Định; bà mẹ hợp tác, đồng ý tham gia nghiên cứu.

Tiêu chuẩn loại trừ: bà me từ chối tham gia nghiên cứu, bà mẹ có biểu hiện rối loạn tâm thần, điếc...

\section{2 Địa điểm và thời gian nghiên cứu}

Nghiên cứu được thực hiện tại 3 xã bao gồm thị trấn Nam Giang huyện Nam Trực, xã Nghĩa Sớn huyện Nghĩa Hưng và xã Xuân Ninh huyện Xuân Trường từ tháng từ tháng 09 năm 2020 đến tháng 2 năm 2021.

2.3 Thiết kế nghiên cứu. Nghiên cứu được tiến hành theo phương pháp mô tả cắt ngang.

2.4 Cỡ mẫu nghiên cứu. Áp dụng công thức tính cõ mẫu so sánh 1 tỷ lệ :

$$
\mathrm{n}=\mathrm{Z}^{(1-\alpha / 2)} \frac{p(1-p)}{d^{2}}
$$

Trong đó: $\mathrm{n}$ là số bà mẹ đang nuôi con dưới 5 tuổi cần nghiên cứu; $\mathrm{p}$ là ước tính tỷ lệ bà mẹ có kiến thức đúng về phòng chống ho gà̀, $\mathrm{p}=0,5$; d: Độ chính xác tuyệt đối (lấy $\mathrm{d}=0,05)$; a: Chọn mức ý nghĩa thống kê $95 \%$, có $a=0,05$. Thay vào công thức ta có $n=384$. Thực tế chúng tôi đã điều tra 384 bà me đang nuôi con dưới 5 tuổi.

2.1 Phương pháp chọn mẫu. Tại mỗi xã được chọn, tiến hành lập danh sách các bà mẹ đang nuôii con dưới 5 tuổi, tiến hành chọn mẫu theo phương pháp cổng liền cổng đến khi đủ cỡ mẫu thì dừng lại. Cõ̃ mẫu cho nghiên cứu kiến thức thực hành của bà me là 384 .

Có 3 xã trong nghiên cứu, như vậy số mà mẹ điêu tra là 128 bà mẹ/xã.

2.2 Biến số trong nghiên cứu. Các biến số về nhân khẩu học của đối tượng: tuổi, trình độ học vấn, nghề nghiệp, số con, nghe thông tin về phòng chống bệnh ho gà.

Các biến số về kiến thức của bà mẹ:Tác nhân gây bệnh ho gà, nguồn lây bệnh ho gà, đường lây truyền bệnh ho gà, lứa tuổi mắc ho gà, các biểu hiện mắc ho gà, các biến chứng khi mắc ho gà, yếu tố nguy cơ mắc bệnh ho gà, các biện pháp phòng chống bệnh ho gà, vắc xin phòng bệnh, chăm sóc trẻ khi bị bệnh.

Các biến số về thực hành của bà mẹ: Tiêm chủng phòng bệnh cho trẻ, tiếp xúc với người có biểu hiện bệnh, vệ sinh nhà cửa, vệ sinh dụng cụ, đồ chơi, vệ sinh cá nhân

\subsection{Phương pháp thu thập thông tin}

- Thành lập 3 đoàn điều tra, mỗi đoàn gồm 4 người, mỗi đoàn được chia theo khu vực để điều tra. Tất cả cán bộ điều tra đều đã được tập huấn kĩ trước khi đi điều tra.

- Thông tin được thu thập thông qua phỏng vấn trực tiếp các bà me có con dưới 5 tuổi theo bộ câu hỏi đã được chuẩn bị trước tại nhà các mẹ đã được cán bộ y tế xã đặt lịch hẹn trước khi cán bộ điều tra xuống địa bàn.

\subsection{Tiêu chí đánh giá trong nghiên cứu}

- Tiêu chuẩn đánh giá kiến thức: phần kiến thức về bệnh có 14 câu hỏi trong đó có 35 ý trả lời (nhiêu câu hỏi có nhiều lựa chọn), bà mẹ được đánh giá đạt về kiến thức khi trả lời đúng $60 \%$ các đáp án đúng.

- Tiêu chuẩn đánh giá thực hành: phần thực hành về bệnh có 11 câu hỏi bà me được đánh giá đạt về thực hành khi trả lời đúng $60 \%$ các đáp án đúng.

2.9 Phương pháp xử lý số liệu. Số liệu được kiểm tra kỹ trước khi nhập, nhập bằng phần mềm Epidata 3.1 và phân tích bằng SPSS21. Các biến định lượng sẽ được trình bày bằng tỷ lệ $\%$, các biến liên tục được trình bày bằng trung bình và độ lệch chuẩn. Sử dụng mô hình hồi quy Logistic đớn biến và đa biến xác định các yếu tố liên quan đến kiến thức, thực hành phòng bệnh ho gà của các bà mẹ đang có con dưới 5 tuổi. Các yếu tố liên quan trong hồi quy đa biến được xác định với mức ý nghĩa $p<0,05$. 
2.10. Đạo đức trong nghiên cứu. Nghiên cứu được sự chấp nhận của Lãnh đạo Trung tâm Kiểm soát bệnh tật Nam Định, các Trung tâm $Y$ tế huyện/thành phố, các Trạm Y tế xã được chọn nghiên cứu. Các bà mẹ tự nguyện tham gia, các thông tin cá nhân được giữ bí mật và chỉ phục vụ cho nghiên cứu và xây dựng kế hoạch phòng chống bệnh ho gà tại địa phương trong những năm tới.

\section{KẾT QUẢ NGHIÊN CỨU}

Trong số 384 bà mẹ tham gia nghiên cứu có $32,2 \%$ bà me độ tuổi từ 25-29 tuổi; $29,2 \%$ là công nhân; $45,1 \%$ có trình độ học vấn là trung học cơ sở và $44,3 \%$ bà mẹ có 2 con.

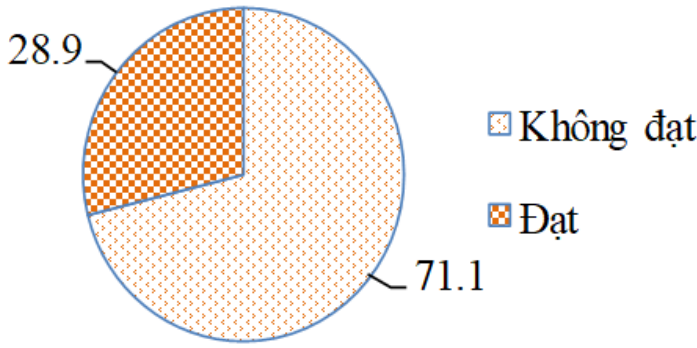

\section{Hình 1. Tỷ lệ bà me có kiến thức đạt về bệnh ho gà}

Hình 1 cho thấy: trong số các bà me được nghiên cứu chỉ có 111 bà me đạt về kiển thức phòng chống bênh ho gà (chiếm 28,9\%), vẫn có $71,1 \%$ bà me chưa đạt về kiến thức trong phòng chống bệnh ho gà.

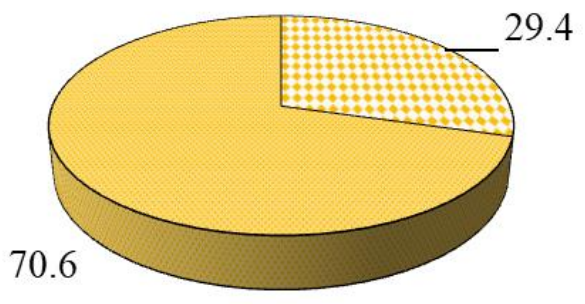

$$
\text { घKhông đạt } \quad \square Đ a ̣ t
$$

Hình 2: Tỷ lệ bà me có thức hành đạt về phòng chống ho gà

Hình 2 cho kết quả, số bà mẹ đạt thực hành về phòng bệnh ho gà chiếm $70,6 \%$ và $29,4 \%$ thực hành phòng bệnh chưa đạt.

Bảng 1. Hồi quy đa biến các yếu tố liên quan tới không đạt kiến thức phòng bệnh ho gà

\begin{tabular}{|c|c|c|c|}
\hline \multicolumn{2}{|c|}{ Biến số } & OR (95\%CI) & P \\
\hline \multirow{3}{*}{ Huyện } & $\begin{array}{c}\text { Xuân } \\
\text { Trường }\end{array}$ & 1 & \\
\cline { 2 - 4 } & $\begin{array}{c}\text { Nghĩa } \\
\text { Hưng }\end{array}$ & 3,34 \\
& $(1,80-6,17)$ & $<0,001$ \\
\hline
\end{tabular}

\begin{tabular}{|c|c|c|c|}
\hline & Nam Trực & $\begin{array}{c}2,68 \\
(1,46-4,92)\end{array}$ & 0,001 \\
\hline \multirow{4}{*}{ Tuổi } & $<25$ tuối & 1 & \\
\hline & 25-29 tuổi & $\begin{array}{c}0,92 \\
(0,45-1,88)\end{array}$ & $>0,05$ \\
\hline & 30-34 tuổi & $\begin{array}{c}0,74 \\
(0,35-1,52)\end{array}$ & $>0,05$ \\
\hline & $\geq 35$ tuổi & $\begin{array}{c}1,26 \\
(0,47-3,37)\end{array}$ & $>0,05$ \\
\hline \multirow{5}{*}{$\begin{array}{l}\text { Nghề nghiệp } \\
\text { của mẹ }\end{array}$} & Nông dân & 1 & \\
\hline & Cán bộ & $\begin{array}{c}0,49 \\
(0,21-1,14)\end{array}$ & $>0,05$ \\
\hline & Công nhân & $\begin{array}{c}0,83 \\
(0,42-1,63)\end{array}$ & $>0,05$ \\
\hline & Buôn bán & $\begin{array}{c}0,91 \\
(0,39-2,12)\end{array}$ & $>0,05$ \\
\hline & Nội trợ & $\begin{array}{c}1,27 \\
(0.60-2.70)\end{array}$ & $>0,05$ \\
\hline \multirow{3}{*}{ Số con } & 1 con & 1 & \\
\hline & 2 con & $\begin{array}{c}2,19 \\
(1,17-4,10)\end{array}$ & $<0,05$ \\
\hline & $\geq 3$ con & $\begin{array}{c}1,46 \\
(0,75-2,81)\end{array}$ & $>0,05$ \\
\hline \multirow{2}{*}{$\begin{array}{l}\text { Nghe thông tin } \\
\text { truyền thông } \\
\text { vê ho gà }\end{array}$} & Có & $\frac{1}{17}$ & \\
\hline & Không & $\begin{array}{c}4,76 \\
(2,66-8,50)\end{array}$ & $<0,05$ \\
\hline
\end{tabular}

Bảng trên cho kết quả hồi quy đa biến các yếu tố liên quan tới kiến thức của bà mẹ. Những bà mẹ sống tại Nghĩa Hưng và Nam Trực có khả năng có kiến thức không đạt cao gấp 3,34 và 2,68 lần so với những bà me sống tại Xuân Trường. Những bà me có 2 con có khả nằng có kiến thức phòng bệnh không đạt cao gấp 2,19 lần so với bà mẹ có 1 con. Bà mẹ chưa từng nghe thông tin truyền thông về ho gà có khả năng có kiến thức không đạt cũng có hơn 4,76 lần so với các bà mẹ đã được nghe thông tin về ho gà.

Bảng 2. Hồi quy đa biến các yêu tồ liên quan tới không đạt thức hành phòng bệnh ho gà

\begin{tabular}{|c|c|c|c|}
\hline \multicolumn{2}{|c|}{ Biến số } & OR(95\%CI) & $\mathbf{p}$ \\
\hline \multirow[t]{3}{*}{ 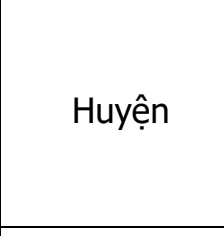 } & $\begin{array}{c}\text { Xuân } \\
\text { Trường }\end{array}$ & 1 & \\
\hline & $\begin{array}{l}\text { Nghĩa } \\
\text { Hưng }\end{array}$ & $\begin{array}{c}0,38 \\
(0,21-0,67)\end{array}$ & 0,002 \\
\hline & $\begin{array}{l}\text { Nam } \\
\text { Trực }\end{array}$ & $\begin{array}{c}0,27 \\
(0,15-0,49)\end{array}$ & $<0,001$ \\
\hline \multirow{4}{*}{$\begin{array}{c}\text { Trình độ học } \\
\text { vân }\end{array}$} & $\begin{array}{c}\text { Cao } \\
\text { đằng/ĐH }\end{array}$ & 1 & \\
\hline & Cấp 1 & - & \\
\hline & Cấp 2 & $\begin{array}{c}1,23 \\
(0,68-2,31)\end{array}$ & 0,455 \\
\hline & Cấp 3 & $\begin{array}{c}1,99 \\
(1,05-3,80)\end{array}$ & 0,035 \\
\hline Nghe thông tin & Có & 1 & 0,138 \\
\hline
\end{tabular}




\begin{tabular}{|c|c|c|c|}
\hline $\begin{array}{c}\text { truyên thông } \\
\text { về ho gà }\end{array}$ & Không & $\begin{array}{c}1,46 \\
(0,88-2,42)\end{array}$ & \\
\hline \multirow{2}{*}{ Kiến thức } & Đật & 1 & \multirow{2}{*}{0,110} \\
\cline { 2 - 3 } & $\begin{array}{c}\text { Không } \\
\text { đạt }\end{array}$ & $\begin{array}{c}1,59 \\
(0,89-2,83)\end{array}$ & \\
\hline
\end{tabular}

Bảng 2 cho kết quả: có 2 yếu tố liên quan tới thực hành của bà me là nơi ở và trình đô học vấn: bà me sống tai Nghĩa Hưng và Nam Trực có khả năng có thực hành không đạt chỉ bằng 0,41 và 0,29 lần so với các bà mẹ sống tại Xuân Trường, các bà mẹ có trình độ học vấn cấp 3 có khả năng có thực hành không đạt cao gấp 1,99 lần so với bà mẹ có trình độ cao đẳng, đại học.

\section{BÀN LUẬN}

Vê kiến thức, thực hành phòng bệnh ho gà ở các bà mẹ: Kểt quả chung về kiển thức phòng bệnh ho gà của bà me cho thấy chỉ có $28,9 \%$ số bà me tham gia nghiên cúu đạt kiến thức. So với nghiên cứu của Đoàn Văn Dương về hiểu biết phòng chống bệnh sởi thì có $22,4 \%$ bà mẹ có kiến thức tốt về phòng bệnh sởi thì số liệu của chúng tôi cũng tương đương với tác giả trền [7]. Tuy nhiên tỷ lệ bà mẹ có thực hành đạt về phòng chống ho gà cao hơn nhiều- đạt $70,6 \%$. Kết quả này khác với các kết quả của các tác giả trên thế giới cho rằng, kiến thức tốt sẽ dẫn tới thực hành tốt [8]. Sự khác biệt này có thể do sự khác nhau về địa bàn, văn hóa sống, cách chọn mẫu hay bộ công cụ đo lường của mỗi nghiên cứu.

Về một số yểu tố liên quan: Nghiên cứu chỉ ra các yếu tố: nơi ở, số con và nghe thông tin truyền thông về ho gà có ảnh hưởng với kiến thức của đối tượng nghiên cứu. Về nơi ở bà mẹ sống tại huyện Nghĩa Hưng và Nam Trực có khả năng không đạt kiến thức phòng bệnh ho gà cao hơn các bà mẹ sống tại huyện Xuân trường gấp 3,34 và 2,68 lẩn. Điêu này có thể được lý giải vì huyện Xuân Trường số bà me là nông dân chiếm chủ yếu, nghề nghiệp này giúp cho cá bà mẹ có nhiều điều kiện về thời gian cũng như không di chuyển nhiều để đi làm nên dễ tiếp cận với các nguồn thông tin về phòng chống dịch như cán bộ y tế, tranh ảnh, áp phích và loa truyền thanh của địa phương. Tầm quan trọng của công tác truyền thông cũng được thể hiện qua nghiên cứu của chúng tôi khi kết quả chỉ ra rằng, bà me không được nghe các thông tin về ho gà có khả năng có kiến thức không đạt cao gấp 4,76 lần so với bà mẹ có nghe các thông tin về bệnh. Ngoài ra bà mẹ có 2 con có khả năng có kiến thức không đạt cao gấp 2,19 lần so với bà me có 1 con, điều này cũng dế lý giải bởi khi lần đầu tiên có con, bà mẹ sẽ có tâm lý dồn sự chăm sóc vào
1 đứa trẻ, sẽ chú ý hơn với bất cứ thay đổi nào của trẻ và cũng tham khảo nhiều thông tin hơn về cách chăm sóc trẻ cũng như các mũi tiêm phòng cho trẻ.

Nghiên cứu còn chỉ ra có mối liên quan có ý nghĩa thống kê giữa thực hành với nơi ở và trình độ học vấn. Các bà mẹ sống tại Nghĩa Hưng và Nam Trực có khả năng có thực hành không đạt chỉ bằng 0,41 và 0,29 lần so với các bà mẹ sông tại Xuân Trường. Điều này có thể là do tỷ lệ các bà me có trình độ học vấn cao trung cấp/cao đẳng/đại học tại huyện Nam Trực là 30,5\% cao hơn so với các huyện còn lại, trình độ học vấn cao giúp cho các bà me biết được mình nên làm gì để chăm sóc con cái một cách tốt nhất bởi trình độ học vấn được chỉ ra là một trong những yếu tố có liên quan mật thiết với thực hành phòng bệnh [9]. Ngoài ra trình độ học vấn cao hơn có thể giúp cho bà mẹ có thu nhập cao hơn các bà me khác, trong khi thu nhập được chỉ ra là một trong những yếu tố có tác động tới tỷ lệ tiêm chủng của trẻ [10]. Trình độ học vấn cũng là một yếu tố tác động tới thực hành phòng bệnh, các bà me có trình độ học vấn cấp 3 có khả năng thực hành không đạt cao gấp 1,99 lần so với bà mẹ có trình độ cao đẳng, đại học.

Khác với các kết quả của các tác giả trên thế giới cho rằng, kiến thức tốt sẽ dẫn tới thực hành tốt [8]. Kết quả trong nghiên cứu của chúng tôi thây rằng không có mối liên quan giữa kiến thức và thực hành phòng chống ho gà. Điều này có thể là do nhiều yếu tố: (1) các kiến thức về bệnh ho gà là những kiến thức chuyên môn, đôi khi các bà me không biết đến những kiến thức đó nhưng lại biết rõ cách phòng bệnh nói chung, bởi ho gà cũng là một trong số các bệnh truyền nhiểm. (2) sau khi bùng phát đại dịch Covid 19, công tác truyền thông giáo dục sức khoẻ về phòng chống bệnh Covid được đẩy mạnh sâu rộng tới từng thôn xã, hộ gia đình, trong khi đó các cách thực hành phòng bệnh Covid có nhiều điểm trùng khớp với thực hành phòng ho gà như vệ sinh nhà cửa, vệ sinh đồ dùng, vệ sinh cá nhân, tránh tiếp xúc với các trường hợp ho.... Do đó phần lớn các bà me đều có những thực hành đúng về cách phòng bệnh ho gà nói riêng và các bệnh truyền nhiễm nói chung.

\section{KẾT LUÂN}

Tỷ lệ bà me đạt kiến thức chung về phòng bệnh ho gà thấp (28,9\%), tuy nhiên tỷ lệ bà mẹ có thực hành phòng bệnh ho gà đạt khá cao $(70,6 \%)$. Các yếu tố liên quan tới kiến thức của bà mẹ là: địa điểm sinh sống, số con của bà mẹ 
và tiếp cận được nguồn thông tin truyền thông về ho gà. Nghiển cứu có tìm thấy mối liên quan có ý nghĩa thống kê giữa thực hành với nơi ở và trình độ học vấn. Công tác truyền thông, giáo dục sức khoẻ cần phải được tăng cường hơn nữa, lựa chọn các phương pháp truyền thông phù hợp, thời điểm truyền thông thích hợp, nâng cao năng lực cho đội ngũ cán bộ y tể,... giúp nâng cao kiến thức, thực hành phòng bệnh của các bà mẹ.

\section{TÀI LIÊU THAM KHẢO}

1. Karene Hoi Ting Yeung, Philippe Duclos, E Anthony $\mathbf{S}$ Nelson, Raymond Christiaan W Hutubessy An update of the global burden of pertussis in children younger than 5 years: a modelling study. Lancet Infect Dis, 17(9), 974-980.

2. WHO Immunization. <https://www.who.int/ data/maternal-newborn-child-adolescent-ageing/ advisory-groups/gama/activities-of-gama>, accessed: 19/04/2021.

3. Thisyakorn U., Tantawichien T., Thisyakorn C. và công sự. (2019). Pertussis in the Association of Southeast Asian Nations: epidemiology and challenges. International Journal of Infectious Diseases, 87, 75-83.

4. Bô Y tế (2018), Niên giám thống kê $Y$ tế 2018 , .

5. Bộ Y tế (2020). Quyết định ban hành kế hoạch phòng, chống dịch bệnh truyền nhiễm năm 2020.

6. Nguyến Thị Thanh Hương (2015), Thực trạng kiến thức, thực hành tiêm chủng đầy đủ cho trẻ dưới 1 tuổi của các bà mẹ và một số yếu tố liên quan tại Móng cái, Quảng Ninh, Luâan văn Thạc sỹ Y tế công cộng, Trường Đại học Y tể Công Cộng.

7. Đoàn Văn Dương (2017), Thực trạng dịch sởi, công tác đáp ứng phòng chống dịch và kiến thức, thực hành của bà mẹ về bệnh sởi tại 5 xã của huyện Ngoc Lăc tỉnh Thanh Hoá năm 2016, Luận văn Thạc sỹ Y tế công cộng, Đại học Y Dược Thái Bình.

8. Linus J. Dowell (2015). The Relationship between Knowledge and Practice. The Journal of Educational Research, 62(5), 201-205.

9. Leon Feinstein, Ricardo Sabates, Tashweka M. Anderson (2006). What are the effects of education on health?

10. Grant C.C., Roberts M., Scragg R. và cộng sư. (2003). Delayed immunisation and risk of pertussis in infants: unmatched case-control study. BMJ, 326(7394), 852-853.

\section{ĐĂC ĐIỂM TỔN THƯƠNG DA DÀY -TÁ TRÀNG Ở BỆNH NHÂN VIÊM KHỚP DÂNG THẤP Có SỬ DUUNG GLUCOCORTICOID}

\section{Lê Thị Thanh Ngà1, Hoàng Văn Dũng ${ }^{2}$, Nguyễn Hoài $\mathrm{Nam}^{3}$}

\section{TÓM TẮT}

Mục tiêu: Mô tả đặc điểm tổn thượng dạ dày - tá tràng theo thang điểm Lanza sửa đổi ở bệnh nhân viêm khớp dạng thấp sử dụng glucocorticoid. Đối tượng và phương pháp nghiên cứu: Nghiên cứu trên 55 bệnh nhân được chẩn đoán viêm khớp dạng thấp có sử dụng glucocorticoid. Tất cả bệnh nhân được khảo sát các chỉ số về đặc điểm bệnh viêm khớp dang thấp, tình trang sử sụng glucocorticoid (GC) và nội soi dạ dày - tá tràng đánh giá các tổn thương dạ dày tá tràng theo thang điểm Lanza sửa đổi. Kết quả: tuổi trung bình là 56,09 $\pm 12,17$ tuổi $(28 \div 76)$, thời gian mắc bệnh trung bình là 54,65 tháng $(1 \div 240)$, mức độ hoạt động bệnh DAS28 - CRP là 4,04 $\pm 1,34$. $40 \%$ bệnh nhân có triệu chứng lâm sàng đường tiêu hóa và $18,2 \%$ bênh nhân có tổn thương dạ dày tá tràng trên nội soi, điểm Lanza sửa đổi trung bình là 0,6 $\pm 1,396$. Kết luận: bệnh nhân viêm khớp dạng

\footnotetext{
${ }^{1}$ Đai hoc Y Hà Nôi,

²Bệnh viện đa khoa quốc tế Hải Phòng

${ }^{3}$ Bềnh viện Bach Mai

Chịu trách nhiệm chính: Lê Thị Thanh Ngà

Email: lethanhnga1409@gmail.com

Ngày nhận bài: 18.6.2021

Ngày phản biện khoa học: 16.8.2021

Ngày duyệt bài: 15.8.2021
}

thấp có sử dung glucocorticoid có $18,2 \%$ có tổn thương dạ dày tá tràng trên nội soi dạ dày tá tràng.

Tư khóa: viêm khớp dạng thấp, glucocorticoid, thang điểm Lanza sửa đổi.

\section{SUMMARY}

\section{THE CHARACTERISTICS OF GASTRODUODENAL INUURY IN RHEUMATOID ARTHRITIS PATIENTS USED GLUCOCORTICOID}

Objective: Describe the characteristics of gastrodoudenal injury based on the modified Lanza score in rheumatoid arthritis patients used glucocorticoid. Subjects and methods: 55 rheumatoid arthritis patients, who treated with glucocorticoid, underwent gastrointestinal endoscope. All patients were surveyed for characteristics of rheumatoid arthritis, glucocorticoid using (GC) and gastroscopy - duodenum assessed for gastric lesions based on the modified Lanza score. Result: The average age was $56,09 \pm 12,17$ years $(28 \div 76)$, the disease duration was 54,65 months $(1 \div 240)$, DAS28 - CRP was $4,04 \pm 1,34$. $40 \%$ of patients had clinical symptoms of the gastrointestinal tract and The prevalence of gastrodoudenal injury was $18,2 \%$ of patients had gastroduodenal injury on gastroduodenal endoscopy, the modified Lanza score was 0,6 $\pm 1,396$. Conclusion: $18,2 \%$ of patients with rheumatoid arthritis using glucocorticoids had gastroduodenal injury on gastroduodenal endoscopy. 